\title{
Can we ignore changing $P$ wave polarity?
}

\author{
Swati Chhabra and Suresh Kumar Singhal \\ Department of Anesthesiology, Pt. BD Sharma Post Graduate Institute of Medical Sciences, Rohatk, India
}

Changing $\mathrm{P}$ wave polarity is a known entity, although there are very few reports on it involving patients with symptomatic cardiac disease. However, little has been reported on this entity during the perioperative period. Not long ago, we reported the case of a 61-year-old woman scheduled for an orthopedic procedure under spinal anesthesia. Spontaneous changes in $\mathrm{P}$ wave polarity were detected intraoperatively, although the patient was asymptomatic and the intra- and postoperative courses were uneventful [1].

Recently, we encountered a similar situation in an asymptomatic 65-year-old woman scheduled to undergo laparoscopic cholecystectomy. A cardiologist's opinion was sought and no cardiac compromise was observed. She underwent the procedure under general anesthesia.
The detection of two such cases within a short time span raises questions about the true incidence and causes of this entity and its relevance to anesthesiologists. It is likely that intraoperative changes in $\mathrm{P}$ wave polarity might go unnoticed despite continuous monitoring of the electrocardiogram if there are no changes in heart rate and rhythm. In a reported case involving an asymptomatic patient, spontaneous changes in $\mathrm{P}$ wave polarity were due to intermittent changes in internodal conduction, as diagnosed in an electrophysiological study [2]. However, conducting electrophysiological studies in all patients would be irrational.

We hope to highlight this entity and bring it to the notice of anesthesia stalwarts so that we can frame preoperative protocols for such rare events.

\section{References}

1. Chhabra S, Singhal SK. Intraoperative change in P-wave polarity, an accidental finding: Anaesthesiologist's dilemma. Egypt J Anaesth 2015; 31: 197-8.

2. Abedin Z, Geraci AR. Changing P wave polarity. Intermittent posterior internodal conduction. Chest 1976; 70: 792-5.

Corresponding author: Swati Chhabra, M.D.

Department of Anesthesiology, Pt. BD Sharma Post Graduate Institute of Medical Sciences, H.NO.82/32A, Chawla Colony, Rohatk 124001, India Tel: 919468090819 , Fax: 01262353433

E-mail: swati_virgo83@yahoo.co.in

Received: September 2, 2015. Accepted: October 13, 2015.

Korean J Anesthesiol 2016 April 69(2): 200

http://dx.doi.org/10.4097/kjae.2016.69.2.200

(c) This is an open-access article distributed under the terms of the Creative Commons Attribution Non-Commercial License (http://creativecommons.org/ licenses/by-nc/4.0/), which permits unrestricted non-commercial use, distribution, and reproduction in any medium, provided the original work is properly cited. 